\title{
Advancing Concentrating Solar Power Research
}

\section{Researchers at the National Renewable Energy}

Laboratory (NREL) provide scientific, engineering, and analytical expertise to help advance innovation in concentrating solar power (CSP). These technologies capture sunlight to produce heat that is used to drive a thermoelectric generation system such as a steam turbine. The unique feature of CSP is the ability to store heated material (often a liquid) in an inexpensive and efficient thermal energy storage tank. The hot fluid can be tapped after sunset or during cloudy weather to provide renewable electricity on demand.

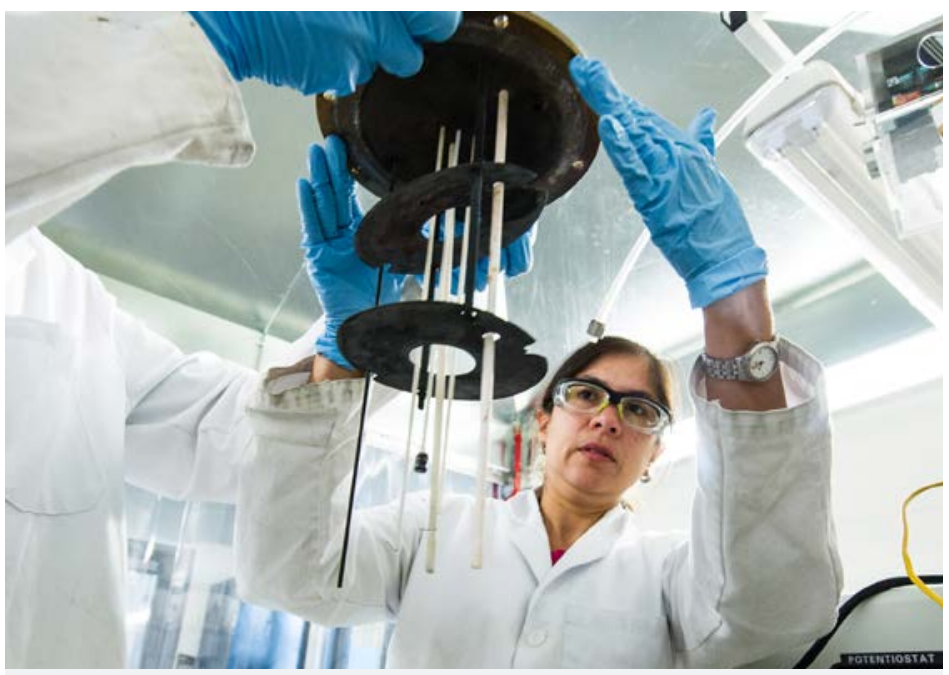

To advance thermal storage capabilities, NREL researchers use a threeelectrode technique for evaluating high-temperature corrosion by molten salts. Photo by Dennis Schroeder, NREL 26587

\section{Helping To Improve a Clean Energy Technology}

$R \& D$ capabilities in CSP span the entire electricity system - from generation to transmission and distribution to the end user-and provide assistance in four major areas of CSP and solar thermal technologies. The key research areas follow.

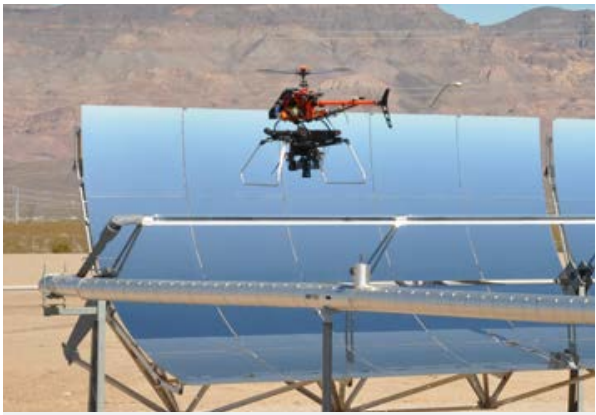

To find flaws in parabolic trough mirrors, a small-scale commercial helicopter with a specialized camera is part of the Distant Observer photogrammetric data acquisition system. Photo from Benjamin Ihas, NREL 23115

\section{Collector and Receiver Characterization}

NREL researchers use a variety of inhouse techniques and tools to test the performance of systems, pinpoint areas of inefficiency, and help identify the most cost-effective design of CSP components.

- At the Concentrator Optical Measurements Laboratory, the Video Scanning Hartmann Optical Test (VSHOT), Sandia Optical Fringe Analysis Tool (SOFAST), photogrammetry, and other state-ofthe-art techniques characterize the optical performance of point- and line-focus optical concentrators.

- On-Sun Parabolic Trough Collector Testing is performed with a two-axis tracker to measure the optical performance of parabolic trough modules.

- The Receiver Test Laboratory measures heat loss as a function of temperature to establish the thermal performance of receiver tubes in parabolic trough systems.
- Thermal Scout uses a vehicle-mounted infrared camera and global positioning system to identify which receivers in an operating parabolic trough plant are losing heat and require maintenance.

- NREL's High-Flux Solar Furnace consists of a $10-\mathrm{m}^{2}$ heliostat and 25 hexagonal mirrors in a parabolic configuration to concentrate sunlight to an intensity of up to 30,000 suns. The furnace tests and evaluates CSP components such as reflector and absorber materials and receivers. It is also used for investigating thermochemical hydrogen and advanced material processes that use high solar flux.

\section{Advanced Reflector and Absorber Materials}

Optical materials-reflectors and absorbers-are critical to CSP systems, and their performance directly affects systemwide efficiency. NREL researchers, often in collaboration with industry partners, 


\section{Thermal Storage and Advanced Heat Transfer Fluids}

The ability to move and store heat is essential for CSP, and cost-effective thermal energy storage enables CSP to provide dispatchable renewable energy.

- Researchers in the Thermal Storage Materials Laboratory evaluate the thermal properties of storage materials and characterize fluids for heat transfer and storage. Thermo-physical properties such as heat capacity, heat of fusion, thermal stability, and viscosity can be measured at high temperature.

- The Thermal Storage Process and Components Laboratory provides high-bay

develop and test CSP optical materials to determine if they meet performance and durability targets.

- Optical characterization involves measuring the reflectance and transmission of CSP mirrors, glazing, lenses, glass, and coatings. In materials characterization, researchers study and quantify the properties of materials such as permeability, adhesion, reflectivity, and absorption.

- Accelerated exposure testing replicates the long-term effects of outdoor exposure in a short period of time. Thus, researchers can assess the durability of CSP reflectors and absorbers in a time frame that supports more rapid deployment of these advanced materials.

\section{- The Thin Film Deposition Laboratory} helps to determine the characteristics and effectiveness of thin-film coatings that protect or enhance the performance of CSP mirrors and receivers.

\section{CSP Modeling and Analysis}

NREL analysts develop and use software tools to facilitate site selection, optimize system design, evaluate cost and performance, and examine the costs and benefits of CSP integration into the power grid. space for pilot-scale testing of thermal storage systems and components.

\section{- With Thermal Storage Heat} Transfer and Fluid-Flow Modeling, computer simulation software is used to model the flow of thermal energy and fluid over time and predict the performance of complex heat-transfer and flow systems.

Advanced modeling techniques and data collection methods help analysts determine the best locations for CSP plants, based on solar irradiance, as well as economic, social, and environmental factors.

Researchers use models and analytical techniques to evaluate the potential for large-scale deployment of CSP under various scenarios and to estimate the resulting impact in terms of energy delivery, jobs, and the environment. Software tools include Systems Advisor Model (SAM), to calculate the performance and levelized cost of CSP system designs; the Regional Energy Deployment System (ReEDS), to determine energy and environmental

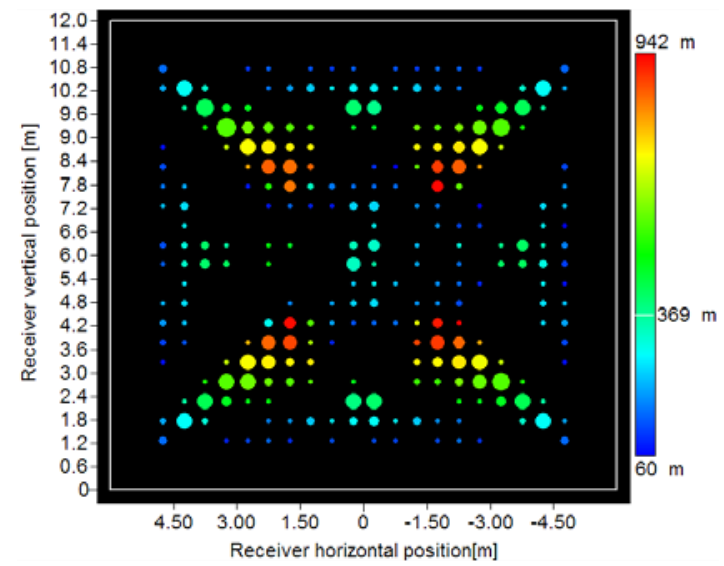

A pickup truck is equipped with Thermal Scout, which helps identify receivers in a parabolic trough plant that are losing heat and require maintenance. Photo by Dennis Schroeder, NREL 20336

impacts; Job and Economic Development Impact (JEDI), to quantify potential employment and financial outcomes; and PLEXOS, to quantify and optimize the integration benefits of dispatchable CSP.

- Detailed thermal, optical, and engineering system modeling is performed using NREL-developed tools such as SAM, SolTrace, and SolarPILOT, as well as commercial software such as Engineering Equation Solver, IPSEpro, ANSYS Fluent, and SolidWorks.

- The Resource Information and Forecasting group provides the necessary solar data, satellite imagery, and geographical information systems to help analysts and stakeholders better understand the feasibility of locating a CSP plant in a particular area.

The Solar Power Tower Integrated Layout and Optimization Tool (SolarPILOT) helps industry address the performance and layout requirements for power tower systems. Source: NREL

NREL CSP Research, www.nrel.gov/csp

Systems Advisor Model (SAM), https://sam.nrel.gov
National Renewable Energy Laboratory

15013 Denver West Parkway, Golden, Colorado 80401 303-275-3000 • www.nrel.gov

NREL is a national laboratory of the U.S. Department of Energy Office of Energy Efficiency and Renewable Energy Operated by the Alliance for Sustainable Energy, LLC
Printed with a renewable-source ink on paper containing at least $50 \%$ wastepaper, including $10 \%$ post consumer waste.

Photo credits (page 1 top, left to right): Building Science Corporation, NREL 13574; Dennis Schroede NREL 26217; iStock 20968071; David Parsons, NREL 01045; Joah Bussert, NREL 20002; iStock 4245455 